\title{
Responses of Bacterial and Fungal Community Structure to Different Rates of 1,3-Dichloropropene Fumigation
}

\author{
Yuan Zeng, ${ }^{1}$ Zaid Abdo, ${ }^{2}$ Amy Charkowski, ${ }^{1}$ Jane E. Stewart, ${ }^{1}$ and Kenneth Frost ${ }^{3, \dagger}$ \\ ${ }^{1}$ Department of Bioagricultural Sciences \& Pest Management, Colorado State University, Fort Collins, CO \\ ${ }^{2}$ Department of Microbiology, Immunology \& Pathology, Colorado State University, Fort Collins, CO \\ ${ }^{3}$ Department of Botany \& Plant Pathology and Hermiston Agricultural Research and Extension Center, Oregon \\ State University, Hermiston, OR
}

Accepted for publication 2 July 2019.

\begin{tabular}{|c|c|}
\hline \multicolumn{2}{|c|}{ ABSTRACT } \\
\hline $\begin{array}{l}\text { 1,3-Dichloropropene (1,3-D) is a well-known nematicidal soil } \\
\text { fumigant on many crop species. Currently, little is known about its } \\
\text { impact on soil microbial communities using culture-free methods. } \\
\text { In this study, we investigated changes in soil bacterial and fungal } \\
\text { diversity and composition at two depths ( } 30.5 \text { and } 61 \mathrm{~cm} \text { ) in } \\
\text { response to management practices of applying } 1,3-\mathrm{D} \text { at four } \\
\text { different rates (103, } 122,140 \text {, and } 187 \text { liters/ha) relative to an } \\
\text { untreated control in potato production fields using } 16 \mathrm{~S} \text { rRNA and } \\
\text { internal transcribed spacer (ITS) amplicon sequencing. A total of } \\
12,783 \text { operational taxonomic units (OTUs) for } 16 \mathrm{~S} \text { and } 1,706 \\
\text { OTUs for ITS were obtained. Sequencing revealed that } \\
\text { Proteobacteria, Firmicutes, Actinobacteria, and Ascomycota were } \\
\text { dominant phyla in soils. Comparing alpha diversity of microbial } \\
\text { communities at the different chemical rates with untreated plots } \\
\text { showed that bacterial communities in plots treated with } 1,3-\mathrm{D} \\
\text { fumigation at } 140 \text { liters/ha were richer, which was supported by }\end{array}$ & $\begin{array}{l}\text { higher richness indices. Other diversity indices and overall soil } \\
\text { microbial community structure were not significantly influenced by } \\
\text { any rates of 1,3-D fumigation, although higher bacterial and fungal } \\
\text { richness and diversity were observed in posttreatment soils and/or } \\
\text { at } 30.5 \mathrm{~cm} \text {. Of the identified microbial families, the differential } \\
\text { abundance of } 45 \text { bacterial and } 24 \text { fungal families was affected by } \\
\text { sample depth, } 1,3-D \text { rate, or the interaction of sample depth and } \\
1,3-D \text {. The bacterial family Enterobacteriaceae, which includes } \\
\text { species that specialize in decay of complex carbohydrates, } \\
\text { increased in abundance post-1,3-D fumigation, and the fungal } \\
\text { family Ophiocordycipitaceae, which includes nematode and insect } \\
\text { pathogens, decreased, suggesting that the nematode and soil } \\
\text { insect death caused by fumigation may selectively impact specific } \\
\text { fungal and bacterial families. } \\
\text { Keywords: crop, management, metagenomics, microbiome }\end{array}$ \\
\hline
\end{tabular}

Over the past few decades, pesticides, including insecticides, fungicides, nematicides, and herbicides, have been increasingly used to improve crop yield and quality. However, widespread adoption and use of pesticides may have unanticipated negative impacts on nontarget organisms and the surrounding ecosystems (Dennis et al. 2018; Pisa et al. 2015; Sugita et al. 2018; Van der

${ }^{\dagger}$ Corresponding author: K. Frost; Kenneth.Frost@oregonstate.edu

Funding: Financial support from Dow AgroSciences was provided to K. Frost and used to support experiment establishment, soil sampling, and DNA sequencing services. This work was funded in part through grants from the U.S. Department of Agriculture NIFA CARE (2017-68008-26496) and SCRI (2018-51181-28704).

*The $\boldsymbol{e}$-Xtra logo stands for "electronic extra" and indicates that 10 supplementary figures and three supplementary tables are published online.

The author(s) declare no conflict of interest.

(C) 2019 The American Phytopathological Society
Sluijs et al. 2015; Zaller et al. 2018). For example, previous studies reported that several pesticides and their degradation products can act as soil pollutants (Sivanesan et al. 2004; Zhang et al. 2016) and applications of pesticides may directly or indirectly alter biological processes in the soil as well as affect soil microbial populations (Ahmed and Ahmad 2006; Imfeld and Vuilleumier 2012; Lewis et al. 2009; Wu et al. 2014). Soil microbial communities support a wide range of ecosystem services required for maintaining soil structure and fertility, supporting carbon, nitrogen, and phosphorus cycling, and removing soil contaminants (Aislabie and Lloyd-Jones 1995; Bending et al. 2007; Dong et al. 2017; Larkin 2003; Singh et al. 2015). Thus, changes to the soil microbial community that occur as a result of agricultural management practices can be used as sensitive indicators of soil processes for evaluation of soil function (Hernández-Allica et al. 2006; Schloter et al. 2018). Therefore, investigating soil microbial community structure and diversity in response to different crop management strategies, including pesticide application, may aid 
farmers in improving sustainability of their management practices (Maul et al. 2014).

The withdrawal of methyl bromide (MeBr), a chemical that has long been used as one of the premier soil fumigants for managing soilborne pests, prompted research to find ecologically acceptable and efficacious alternatives (Liu et al. 2015). Several fumigants, including 1,3-dichloropropene (1,3-D), chloropicrin, and methyl isothiocyanate generators have been registered as $\mathrm{MeBr}$ replacements in many countries (Ajwa et al. 2003; Qiao et al. 2011; Shi et al. 2009). As a well-known nematicide with fungicidal and insecticidal activity, 1,3-D is used in multiple crops. The effects of 1,3-D, when applied alone or in combination with other products, on crop yield, 1,3-D degradation characteristics, and 1,3-D distribution and emission have been extensively studied (Dungan et al. 2003; Ji et al. 2013; Luo et al. 2013; Mao et al. 2017; Qiao et al. 2010, 2011; Qin et al. 2013a, b; Wang et al. 2010).

1,3-D can persist in soils from a few days to several weeks (Dungan et al. 2003; Wang et al. 2010) and may exhibit toxicity to nontarget organisms because of its broad biocidal activity. However, there are relatively few studies that have analyzed the effects of 1,3-D fumigation on the nontarget soil microbial community compared with the number of studies reporting effects on its specific target pests. A previous study used nested PCR-denaturing gradient gel electrophoresis to monitor fungal community structure in bulk soil and spinach rhizosphere soil after 1,3-D fumigation. They found that the fungal community profile and diversity changed 2 months postfumigation but recovered within 6 months postfumigation (Hoshino and Matsumoto 2007). Yet another study investigated bacterial communities in 1,3-D-fumigated soil using 454 pyrosequencing techniques; the authors reported that 1,3-D treatment only increased bacterial diversity and had a suppressive effect on the indigenous soil bacterial populations or abundance at the beginning of the treatments in tomato fields (Liu et al. 2015).

The use of advanced high-throughput sequencing techniques has led to an explosive accumulation of research data and has vastly improved our understanding of the microflora, including species data of unculturable microorganisms in soil (Bai et al. 2014). However, despite the widespread use of 1,3-D as a common practice to reduce the impact of nematodes on many different crops, there are relatively few recent studies that have documented the impact of 1,3-D on the soil microbial community using culture-free methods. The aim of this study was to assess the response of soil microbial communities to the application of four rates of 1,3-D (103, 122, 140, and 187 liters/ha), and the associated soil disturbance, in an Oregon potato field relative to an untreated control, and to determine if 1,3D impacts on microbial community structure varied between two soil depths.

\section{MATERIALS AND METHODS}

Site description, experimental design, and soil sampling. This field experiment was conducted at the Hermiston Agricultural Research and Extension Center (HAREC) south of Hermiston, Oregon during the fall of 2016. The field soil is a fine sandy loam with approximately $65 \%$ sand, $25 \%$ silt, $10 \%$ clay, and less than $1 \%$ organic matter. The previous crop at this location was winter wheat. In early September 2016, fall tillage practices prior to experiment establishment included ripping to a depth of $46 \mathrm{~cm}$, disking twice, and roller-harrowing. The field was watered prior to 1,3-D application to obtain proper soil moisture to a depth of $30.5 \mathrm{~cm}$, assessed by the "feel method" as directed by the pesticide label.

Three replicates of four experimental treatments and one untreated control were arranged in a randomized complete block design. Plot sizes were $9.1 \mathrm{~m}$ wide by $122.9 \mathrm{~m}$ long. Broadcast applications of 1,3-D were shank injected at a depth of $46 \mathrm{~cm}$ by a commercial applicator. The four treatments included different rates of 1,3-D at 103, 122, 140, and 187 liters/ha. A disc and cultipacker, in combination, directly followed the shank, in tow, to seal the soil surface following application. A $9.1 \mathrm{~m}$ border treated with 1,3-D at 122 liters/ha was established around the experiment to reduce edge effects within the experiment. Applications of 1,3-D occurred on 13 September 2016. Air temperature at start of application was approximately $4^{\circ} \mathrm{C}$ and soil temperature at $20 \mathrm{~cm}$ was approximately $19^{\circ} \mathrm{C}$. Since the purpose of this was to examine how the microbial community was affected by farm management practices, the nontreated control did not have additional tillage associated with 1,3-D application.

Soil was sampled on 12 September 2016 prior to 1,3-D application and on 17 October 2016 following application. The posttreatment sample was taken after planting the cover crop since our goal was to determine if 1,3-D application effects could be detected after common farming operations, such as irrigation and cover crop planting, that typically occur shortly after 1,3-D application. As a fall cover crop, winter wheat was drilled into the entire experimental plot in the week of 5 October 2016. The wheat was watered by center pivot irrigation (ca. $0.64 \mathrm{~cm}$ ) immediately after planting and an additional $2 \mathrm{~cm}$ of precipitation occurred prior to the second soil sampling date. To sample soils, field plots were divided in the center, resulting in two subplots of $9.1 \mathrm{~m}$ wide by $61.5 \mathrm{~m}$ long. On each sample date and within each subplot, soil samples were obtained at each of 10 locations at two depths using a zig-zag sampling scheme. Soil samples were collected by two people, the first person collected soil to $30.5 \mathrm{~cm}$ depth and was followed by a second person who collected soil from the same location to a $61 \mathrm{~cm}$ depth. A standard $2.2 \mathrm{~cm} \times 53 \mathrm{~cm}$ soil probe (AMS, American Falls, ID) was used to collect all soil samples. The soil from each of the 10 locations within a subplot and for each sample depth were bulked together in a plastic bag and stored at $4^{\circ} \mathrm{C}$ until further processing. In the laboratory, approximately $2 \mathrm{~g}$ of each soil sample was added to $3 \mathrm{ml}$ of RNAlater (ThermoSci) in a 15-ml Falcon tube (Fisher Sci, Pittsburgh, PA) and samples were shipped to Colorado State University for molecular processing.

Samples were stored at $-20^{\circ} \mathrm{C}$ until DNA extractions occurred. To prepare samples for extraction, each was centrifuged at $2,500 \times g$ for 5 min and RNAlater was removed. DNA from soils were then extracted using the RNA PowerSoil Total RNA Kit and RNA PowerSoil DNA Elution Accessory Kit (MoBio Laboratories, Carlsbad, CA), following manufacturer's instructions with a few modifications. Modifications included adding $2 \mathrm{~g}$ of soil to each bead tube and a reduction in elution buffer from the suggested 100 to $50 \mu \mathrm{l}$.

DNA samples were sent to the University of Minnesota Genomics Center for library preparation and Illumina sequencing of the V4-16S ribosomal RNA (rRNA) gene region using primers V4_515F (GTGCCAGCMGCCGCGGTAA) and V4 806R (GGACTACHV GGGTWTCTAAT) and ITS2 of the internal transcribed spacer (ITS) region using primers ITS3 (GCATCGATGAAGAACGCAGC) and ITS4 (TCCTCCGCTTATTGATATGC). Libraries were then sequenced on a MiSeq PE 300.

Sequence data analysis and statistics. Reads from the forward primer or reverse primer of 16S rRNA and ITS in a few samples were of low quality, thus these reads were discarded (Supplementary Table S1). The remaining reads from either the $5^{\prime}$ or $3^{\prime}$ end were used for sequence data analysis. Contigs were created from the overlapping read-pairs from the other samples, and sequences and PCR errors were then reduced using mothur (https:// www.mothur.org/wiki), in which contigs containing $>312$ base pairs for $16 \mathrm{~S}$ rRNA or $>355$ base pairs for ITS were removed. 
Duplicate sequences and sequences with chimera were also removed by mothur. The resulting optimized sequences were taxonomically classified against SILVA (silva.nr_v128.fasta) or UNITE ITS (UNITEv6_sh_dynamic_s.fasta) databases, and identified to kingdom, phylum, class, order, family, and/or genus levels using the Ribosomal Database Project classifier (Wang et al. 2007) at 80\% threshold. Subsequently, sequences were clustered by distancebased greedy clustering method with VSEARCH (Westcott and Schloss 2015) as implemented in mothur and were classified into operational taxonomic units (OTUs) with $97 \%$ sequence similarity. OTU abundances with sums $=0$ were removed after the sparse abundance (count $\leq 1$ ) was replaced with 0 , and the resulting matrices were used in further analysis.

Plots with low sequences (12 plots with $<10,000$ sequences for $16 \mathrm{~S}$ rRNA and 20 plots with $<4,000$ sequences for ITS; Supplementary Table S2) were removed, and rarefaction curves, distribution of sequencing depth, and microbial community composition of classified phylum, class, order, and families ( $>1 \%)$ were produced in $\mathrm{R}$ (https://www.rstudio.com). Alpha diversity indices including Shannon diversity, InvSimpson diversity, observed richness, and rarefied richness estimates interpolating the minimum sample-specific sequencing depth were calculated with the aid of $\mathrm{R}$ packages phyloseq (McMurdie and Holmes 2013) and vegan (Oksanen et al. 2013). Analysis of variance and Tukey's method were used to compare the mean differences of alpha diversity indices among treatments.

OTU and taxon abundances were normalized with the cumulative sum scaling (CSS) method (Paulson et al. 2013). The CSS normalized matrices after calculation of Bray-Curtis dissimilarity were subjected to nonmetric multidimensional scaling (NMDS) and hierarchical clustering analysis, respectively. Three-dimensional NMDS ordination plots were generated and heatmaps of the top 15 families of bacterial or fungal communities comparing treatment effects were made by averaging and clustering the samples collected from the same treatments with unweighted pair group method with arithmetic mean utilizing the Bray-Curtis similarity index. Furthermore, OTU and taxon abundances on the differences between pre- and posttreatment at the family level (subtractions between post- and pretreatment) were ranked and subjected to a linear mixedeffects regression model with depth and chemical rates as covariates,

TABLE 1

The comparison of alpha diversity indices of microbial communities by analysis of variance

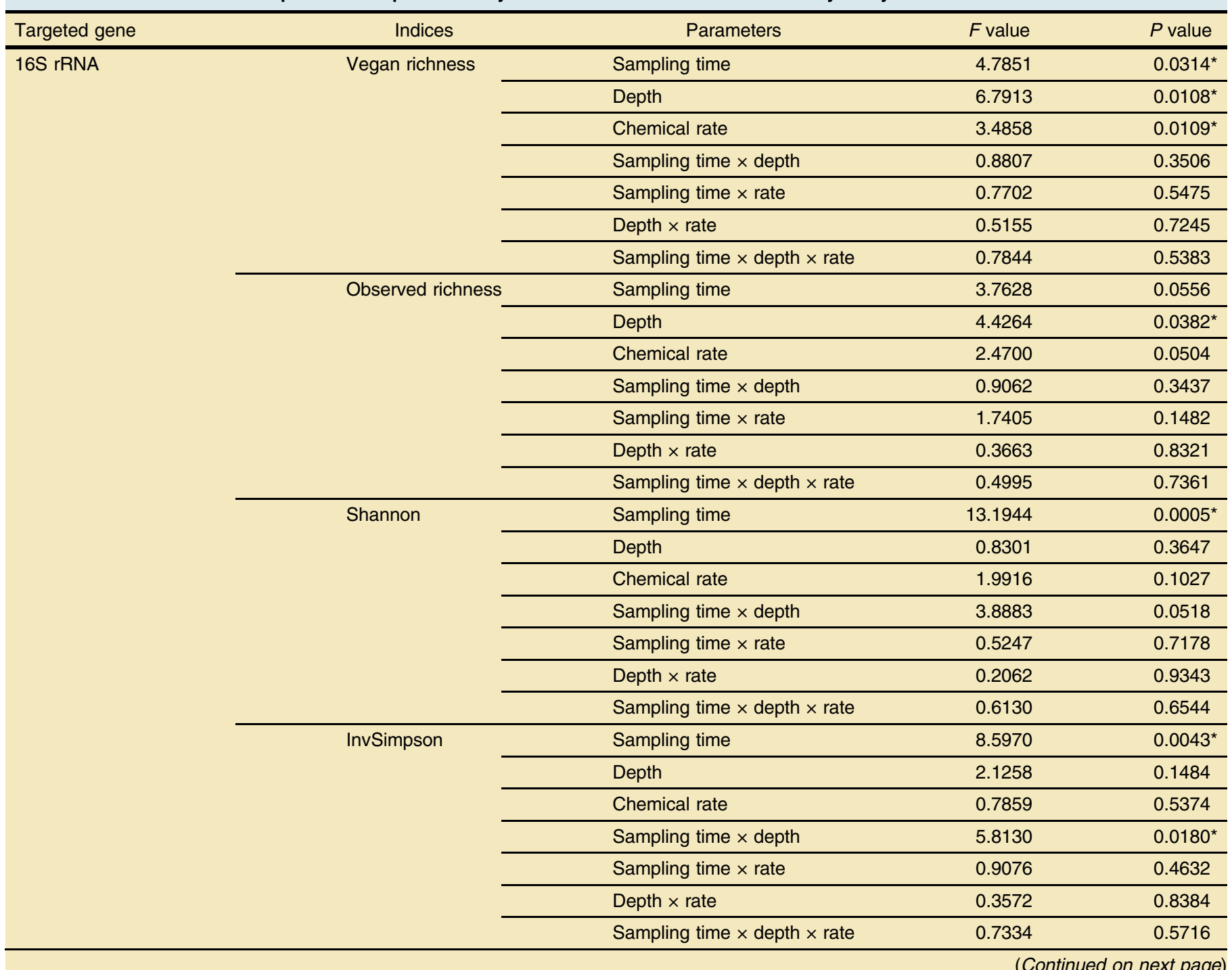

\footnotetext{
${ }^{\mathrm{a}} \alpha=0.05 ;{ }^{*}$ indicates a significant difference.
} 
using rate 0 (untreated control plots) as reference. Differentially abundant families were also determined by comparisons between depth and among chemical rates with untreated control plots. These analyses were performed with the aid of R packages including lme4, metagenomeSeq, vegan, and DESeq2. Statistical significance was assessed at the 0.05 level for all statistical analyses performed.

\section{RESULTS}

Alpha diversity of the microbial community. Bacterial community. After clustering and alignment based on a 0.97 threshold across all samples, we found a total of 12,783 OTUs for $16 \mathrm{~S}$ rRNA with a range of 386 to 1,440 OTUs present in each sample. The lowest number was in the PT2912 sample (DNA extracted at the depth of $30.5 \mathrm{~cm}$ after the plot was applied with 1,3$\mathrm{D}$ at the rate of 187 liters/ha), while the highest number was in the PT2724 sample (DNA extracted at the depth of $61 \mathrm{~cm}$ after the plot was fumigated with 1,3-D at the rate of 140 liters/ha) (Supplementary Fig. S1). Of the identified OTUs, some were exclusively detected in either 1,3-D-fumigated samples $\left(\mathrm{n}_{103}\right.$ liters $/ \mathrm{ha}=907$, $7.88 \% ; \mathrm{n}_{122}$ liters/ha $=1,073,9.33 \% ; \mathrm{n}_{140 \text { liters } / \mathrm{ha}}=1,307,11.36 \%$; $\left.\mathrm{n}_{187 \text { liters/ha }}=1,021,8.87 \%\right)$ or control samples $\left(\mathrm{n}_{0}\right.$ liters/ha $=378$, $3.29 \%$ ), while $59.27 \%$ of OTUs were shared by 1,3 -D-fumigated and control samples (Supplementary Fig. S2). The sequence depth for all of the samples ranged from to 17,429 to 56,088 for bacterial communities. The sequencing depth of 16S rRNA for most samples did not yield saturation, as shown by the rarefraction curves.

All alpha diversity indices, except the observed richness, differed significantly between pre- and posttreatments (Table 1; Supplementary Fig. S3). The indices were higher in the posttreatment than in the pretreatment samples $\left(\right.$ Diff $f_{\text {Pre-Post }}=-59.98, P_{\text {VeganRichness }}=$ 0.0314; Diff ${ }_{\text {Pre-Post }}=-0.30, P_{\text {Shannon }}=0.0005$; Diff ${ }_{\text {Pre-Post }}=-1.46$, $\left.P_{\text {InvSimpson }}=0.0043\right)$. Bacterial communities were more complex at $30.5 \mathrm{~cm}$ depth compared with $61 \mathrm{~cm}$ depth, which was supported by higher vegan richness and observed richness at $30.5 \mathrm{~cm}\left(\right.$ Diff $_{61-30.5}=$ -94.32, $P_{\text {VeganRichness }}=0.0382 ;$ Diff $_{61-30.5}=-71.66, P_{\text {Observed }}=$ 0.0108 ). The InvSimpson diversity index was higher at $30.5 \mathrm{~cm}$ in the posttreatment compared with the pretreatment $\left(\right.$ Diff $_{\text {Pre30.5-Post30.5 }}=$ $-2.94, P_{\text {Pre30.5-Post30.5 }}=0.0017$ ).

Comparing rarified richness of the bacterial communities at the different chemical rates showed that bacterial OTUs were more diverse and abundant in plots treated with 1,3-D fumigation at a rate of 140 liters/ha than in the untreated control (0 liters/ha) or in plots treated with 1,3-D fumigation at 122 liters/ha $\left(\right.$ Diff $_{140-0}=143.18$, $P_{140-0}=0.0112 ;$ Diff $\left._{140-122}=132.89, P_{140-122}=0.0226\right)$. The observed richness of the bacterial community in plots treated with

TABLE 1 (Continued from previous page)

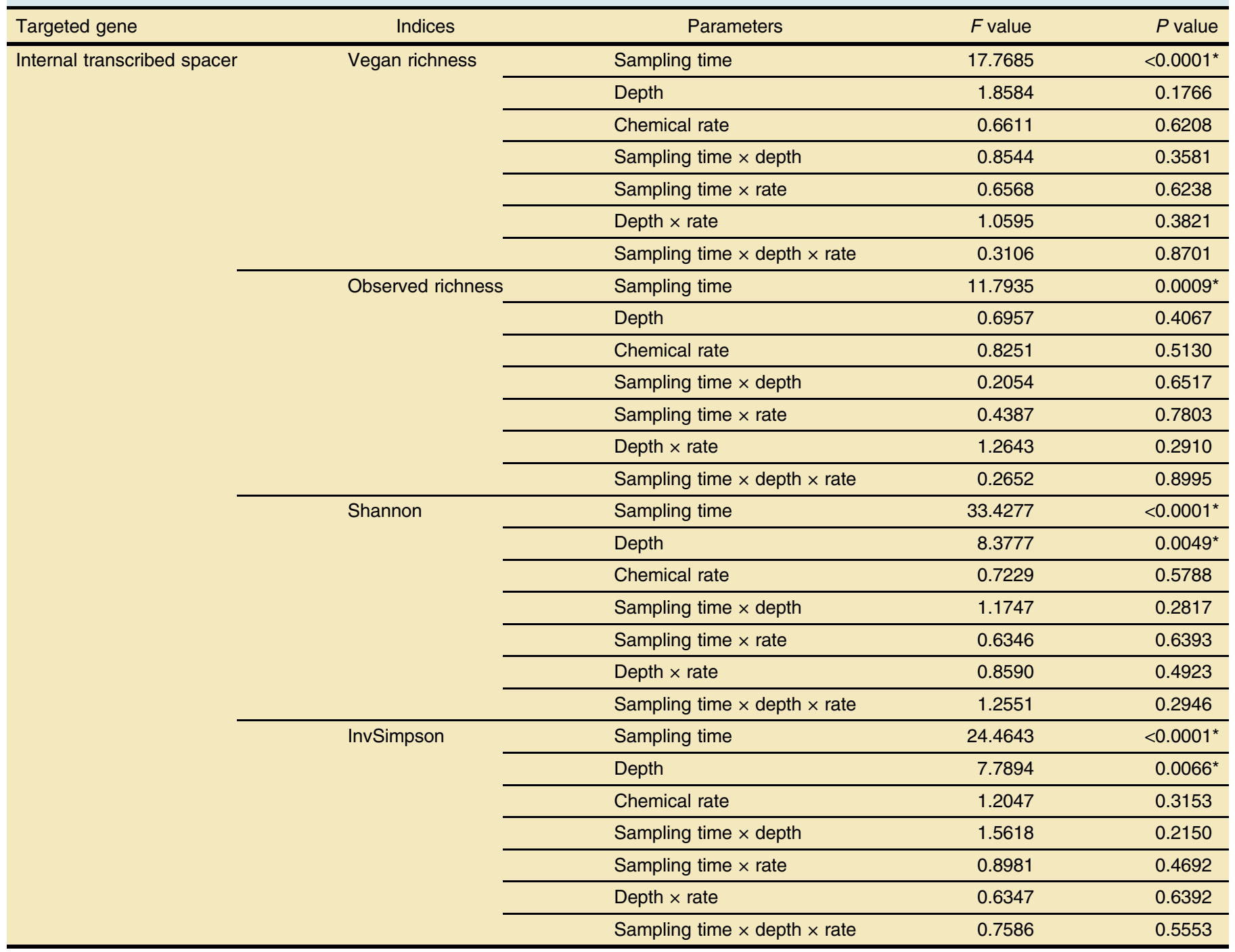


1,3-D at a rate of 140 liters/ha was greater than in control plots $\left(\right.$ Diff $\left._{140-0}=201.67, P_{140-0}=0.0403\right)$. Shannon and InvSimpson diversity indices between 1,3-D-treated and control plots ranged from 0.04 to $0.34(P \mathrm{~s}>0.0803)$ and 0.16 to $1.22(P \mathrm{~s}>0.5947)$, respectively, indicating no significant differences of bacterial community profiles were observed (Supplementary Table S3).

Fungal community. A total of 1,706 OTUs for ITS with a range of 21 to 398 OTUs was present in each sample. The lowest number was observed in PR0212 (DNA extracted from samples collected at a depth of $30.5 \mathrm{~cm}$ in an untreated control plot), while the highest number was in PT0912 (DNA extracted at a depth of $30.5 \mathrm{~cm}$ after treatment with 1,3-D at the rate of 140 liters/ha). Among the identified fungal OTUs, a portion was exclusively detected in either 1,3-D-fumigated samples $\left(\mathrm{n}_{103}\right.$ liters/ha $=28,1.82 \% ; \mathrm{n}_{122}$ liters $/ \mathrm{ha}=73$, $\left.4.74 \% ; \mathrm{n}_{140 \text { liters/ha }}=409,26.58 \% ; \mathrm{n}_{187 \text { liters } / \mathrm{ha}}=148,9.62 \%\right)$ or control samples $\left(\mathrm{n}_{0}\right.$ liters/ha $\left.=284,18.45 \%\right)$, while $38.79 \%$ of OTUs were shared by $1,3-\mathrm{D}$-fumigated and control samples. Sequence depth for all the samples ranged from 4,046 to 41,240 for fungal communities. Compared with the bacterial rarefaction curves, sequencing depth of ITS region was adequate as highlighted by the saturated curves.

All four alpha diversity indices differed significantly between pre- and posttreatment (Table 1). The mean indices were higher in communities of posttreatment samples than in pretreatment samples $\left(\right.$ Diff ${ }_{\text {Pre-Post }}=-19.81, P_{\text {VeganRichness }}<0.0001 ;$ Diff ${ }_{\text {Pre-Post }}=-34.54$, $P_{\text {Observed }}=0.0009 ;$ Diff Pre-Post $=-0.43, P_{\text {Shannon }}<0.0001 ;$ Diff Pre-Post $_{1}=$ $-1.91, P_{\text {InvSimpson }}<0.0001$; Supplementary Fig. S7). In addition, the mean of Shannon and InvSimpson index were higher at $30.5 \mathrm{~cm}$
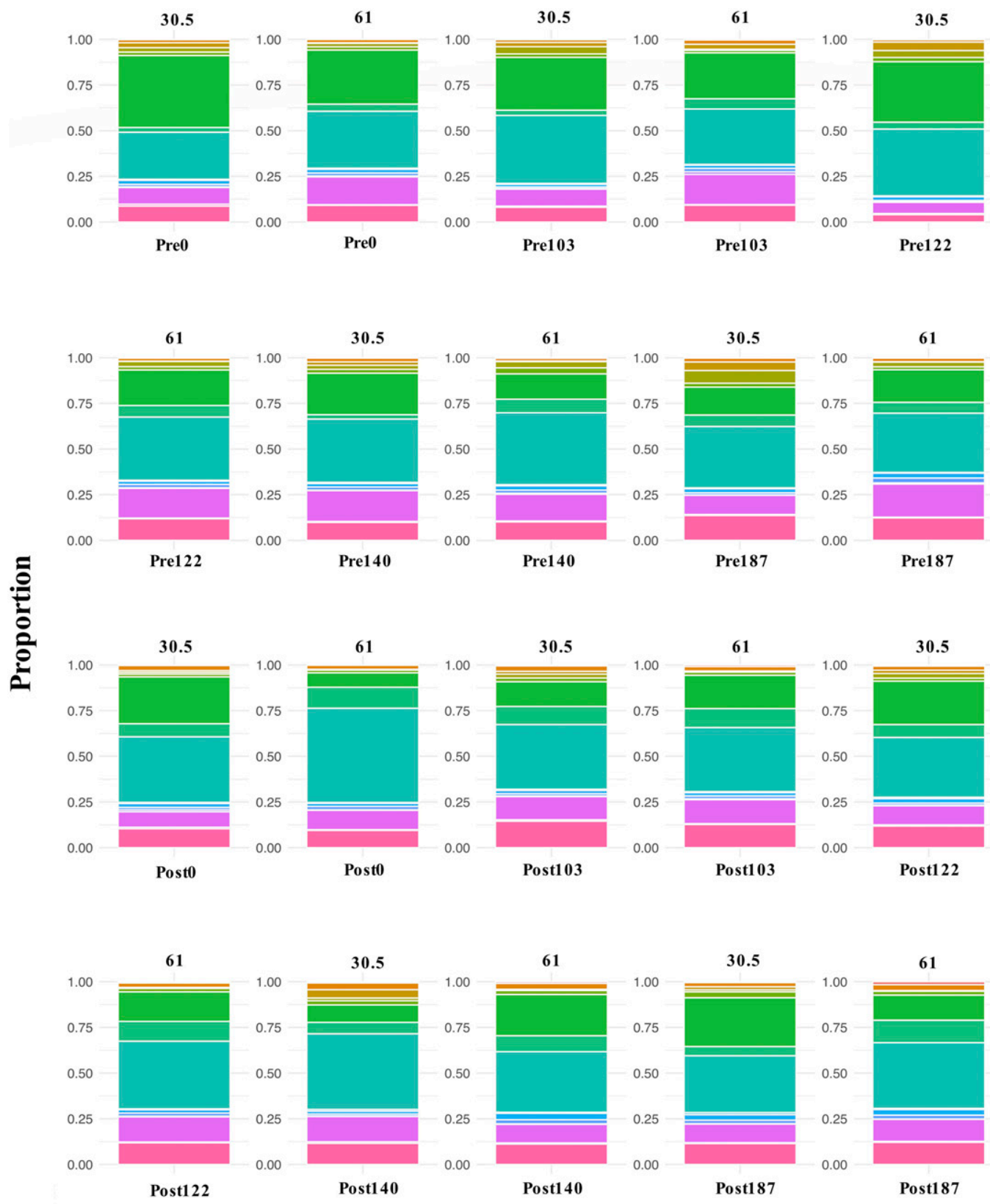

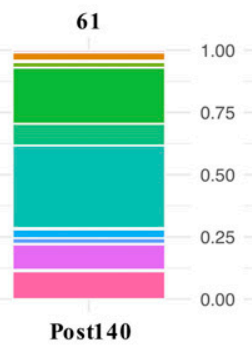

Sample
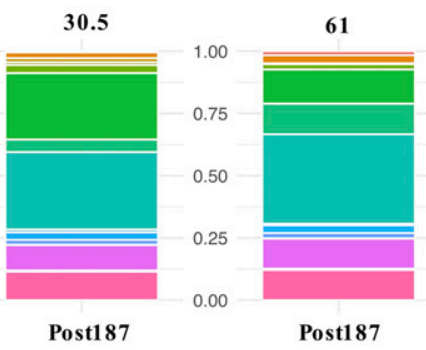

\author{
Family \\ Alcaligenaceae \\ Alphaproteobacteria_unclassified \\ Bacillales_unclassified \\ Bacilli_unclassified \\ Bacteria_unclassified \\ Enterobacteriaceae \\ Firmicutes_unclassified \\ Gammaproteobacteria_unclassified \\ Microbacteriaceae \\ Micrococcaceae \\ Micrococcales_unclassified \\ Pseudomonadaceae \\ Rhizobiales_unclassified \\ Sphingomonadales_unclassified \\ Xanthomonadaceae
}

Fig. 1. Bacterial community composition at family rank (>1\%) presented by plots with different rates of 1,3-dichloropropene applied at two depths in the pre- and posttreatment. 
than at $61 \mathrm{~cm}\left(\operatorname{Diff}_{61-30.5}=-0.20, P_{\text {Shannon }}<0.0049\right.$; Diff $_{61-30.5}=$ $\left.-1.08, P_{\text {InvSimpson }}<0.0066\right)$. 1,3-D fumigation with different rates did not affect alpha diversity indices (Table 1). For example, differences of vegan and observed richness indices between treated and untreated soils ranged from -4.93 to 5.80 ( $P$ s $>0.9325)$ and -8.31 to 17.08 ( $P \mathrm{~s}>0.8112$ ); ranges of differences on Shannon and InvSimpson indices between treated and untreated plots were -0.15 to $-0.009(P \mathrm{~s}>0.6602)$ and -1.10 to $-0.30(P \mathrm{~s}>$ $0.3900)$, respectively.

Microbial community composition. Bacterial community. Out of the quality-filtered reads, 58.9, 52.1, 31.8, 22.5, and $8.1 \%$ could be taxonomically classified to phylum, class, order, family, and genus level for $16 \mathrm{~S}$ rRNA, respectively. When considering the bacterial community composition at phylum, class, order, and family level (relative abundance $>0.1 \%$; Supplementary Fig. S4), the Proteobacteria was the most abundant phylum across all samples. The other dominant phyla were Firmicutes and Actinobacteria. Further comparison of the microbial communities was conducted at the class level. Eight classes were screened (relative abundance $>0.1 \%$ ) in all samples and the most abundant classes were Gammaproteobacteria, Alphaproteobacteria, Firmicutes_ unclassified, Actinobacteria, and Bacilli. Of the most abundant bacterial taxa, Gammaproteobacteria_unclassified was the dominant family, followed by Enterobacteriaceae, and Rhizobiales_ unclassified (Fig. 1).

Bacterial community profiles at the family level were also visualized using a hierarchically clustered heatmap (Supplementary Fig. S5). The samples harvested from the same depth were more closely clustered. Samples collected at $30.5 \mathrm{~cm}$ exhibited a distant relationship with samples collected at $61 \mathrm{~cm}$. Conversely, the relationship between pre- and post-samples were mixed, with some pretreatment samples clustering with posttreatment samples. NMDS plots based on Bray-Curtis dissimilarities of bacterial community composition resulted in two clear clusters of pre- and posttreatment samples, at the two depths, and four clear clusters among two depths of pre- and posttreatment samples (Supplementary

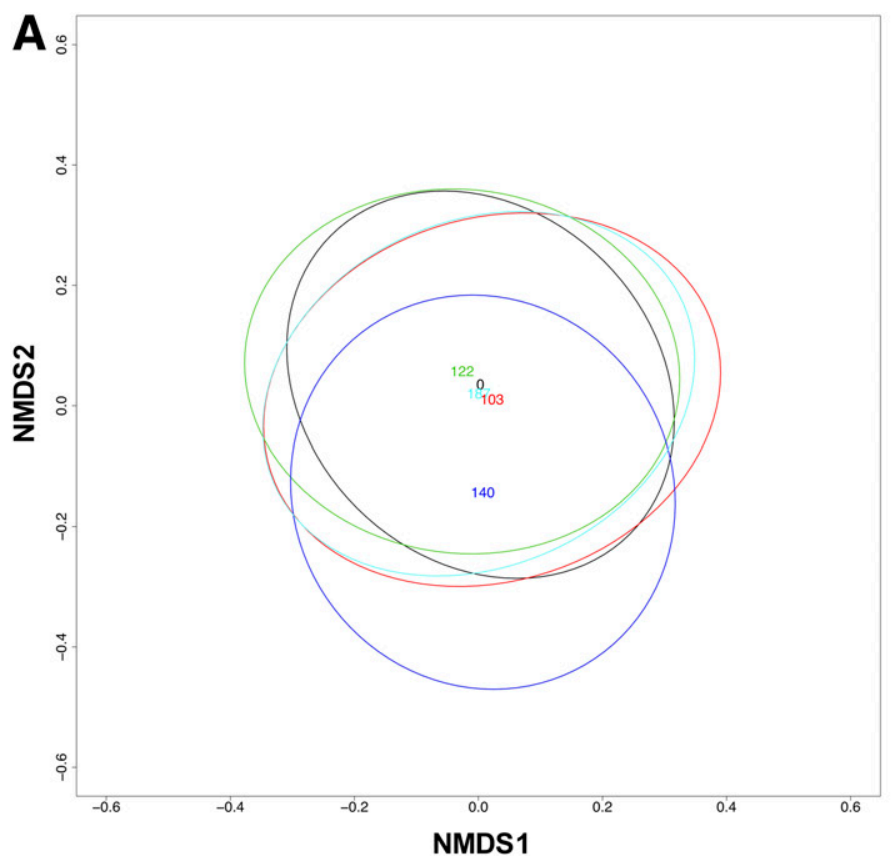

Fig. S6). In contrast, neither the overall bacterial composition in samples with different rates of 1,3-D fumigation nor the comparison of these samples from pre- and posttreatment showed separated clusters (Fig. 2).

Fungal community. Out of the quality-filtered reads, 68.9, $64.2,62.5,58.3,47.4$, and $19.6 \%$ could be taxonomically classified to phylum, class, order, family, genus, and species rank for ITS, respectively. When considering fungal community composition at phylum, class, order, and family level (relative abundance $>0.1 \%$ ), members of the Ascomycota phylum were the most ubiquitous across all samples (Supplementary Fig. S8). Within this phylum, Eurotiomycetes was the dominant class, followed by Sordariomycetes and Saccharomycetes. Fungal orders identified included Hypocreales, Eurotiales, Coniochaetales, Sordariomycetes_sedis, Sordariales and Pleosporales which are commonly found in soil samples. Of the most common fungal taxa, Nectriaceae was the dominant family, followed by Trichocomaceae, Plectosphaerellaceae, Coniochaetaceae, and Hypocreales_sedis (Fig. 3).

Similarly, fungal community profiles at the family level from $30.5 \mathrm{~cm}$ were dissimilar to samples collected at $61 \mathrm{~cm}$, whereas preand post-samples were mostly clustered together (Supplementary Fig. S9). In contrast, three-dimensional NMDS plots of fungal community composition resulted in two clear clusters of pre- and posttreatment samples. Clear separations were also observed from samples collected at two depths and within the same depth between pre- and posttreatment (Supplementary Fig. S10). Similar to bacterial community, there were no separations of overall fungal community structure in samples with different rates of 1,3-D applied, nor the samples comparing the different rates between preand posttreatment (Fig. 4).

Significant differences in microbial communities at family level. Bacterial community. To identify the bacterial families with significant abundance differences between treatments, we performed linear mixed-effect regression models on ranked abundance differences (subtractions between post- and pretreatment). Out of 216 bacterial families, a total of 13 phyla with 45 families showed

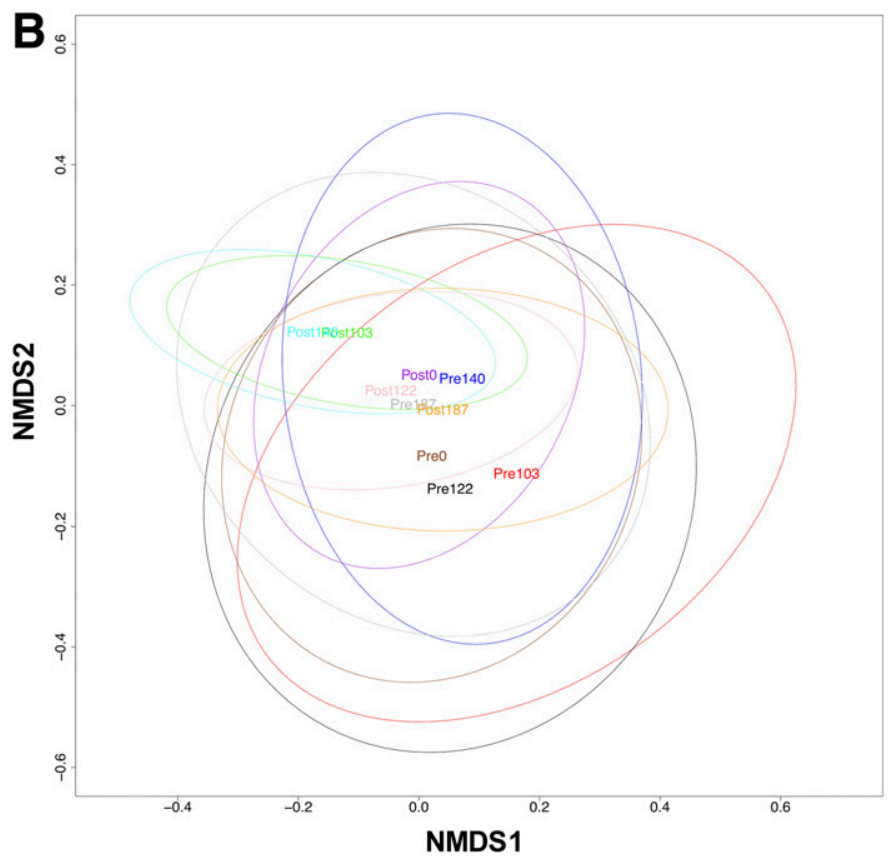

Fig. 2. Two-dimensional nonmetric multidimensional scaling (NMDS) based on Bray-Curtis dissimilarities of bacterial community composition showing community composition $\mathbf{A}$, among different rates of 1,3-dichloropropene (1,3-D) applied to plots and $\mathbf{B}$, among different rates of 1,3-D applied in preand posttreatment. 
changes either between two depths, with different rates of 1,3-D applied, or their interactions (Table 2). Of these, three families had higher abundances and four families had lower abundances in the samples collected at $30.5 \mathrm{~cm}$ than in samples collected at $61 \mathrm{~cm}$. Interestingly, the abundance of the common family Enterobacteriaceae was increased in samples at $30.5 \mathrm{~cm}$.

There were 2, 2, 17, and 14 families that had decreased abundances, while 3, 4, 6, and 3 families had increased abundances in response to 1,3-D fumigation at rates of 103, 122, 140, and 187 liters/ha, respectively. Of the families with decreased abundances, 11 families (Blastocatellaceae_(Subgroup4), Subgroup_6_fa, Subgroup_ 6_unclassified, Acidimicrobiales_unclassified, Corynebacteriales_ unclassified, Saprospiraceae, KD3-93, Rhodospirillales_unclassified, Betaproteobacteria_unclassified, Bacterioboracaceae, and Coxiellaceae) had reduced abundance in plots with 1,3-D at 140 liters/ha. The abundances of 11 families (Chthonomonadales_fa, Bacteroidales_ unclassified, Cyanobacteria_unclassified, Clostridiaceae_1, Selenomonadales_unclassified, 0319-6A21, Planctomycetaceae, Comamonadaceae, Gammaproteobacteria_unclassified, Proteobacteria_unclassified, and Chthoniobacterales_unclassified) were only negatively affected by 1,3-D at 187 liters/ha. There were three families, including C0119_fa, Tepidisphaeraceae, and UA11_fa, that had lower abundances in plots where 1,3-D was applied at rates of 140 and 187 liters/ha. The abundances of Firmicutes_ unclassified and Rhodospirillaceae decreased in plots treated with 1,3-D at rates of 103 and 140 liters/ha, as well as a decreased abundance of Rhizobiales_Incertae_Sedis in plots treated with 1,3-D at rates of 122 and 140 liters/ha. However, one family,
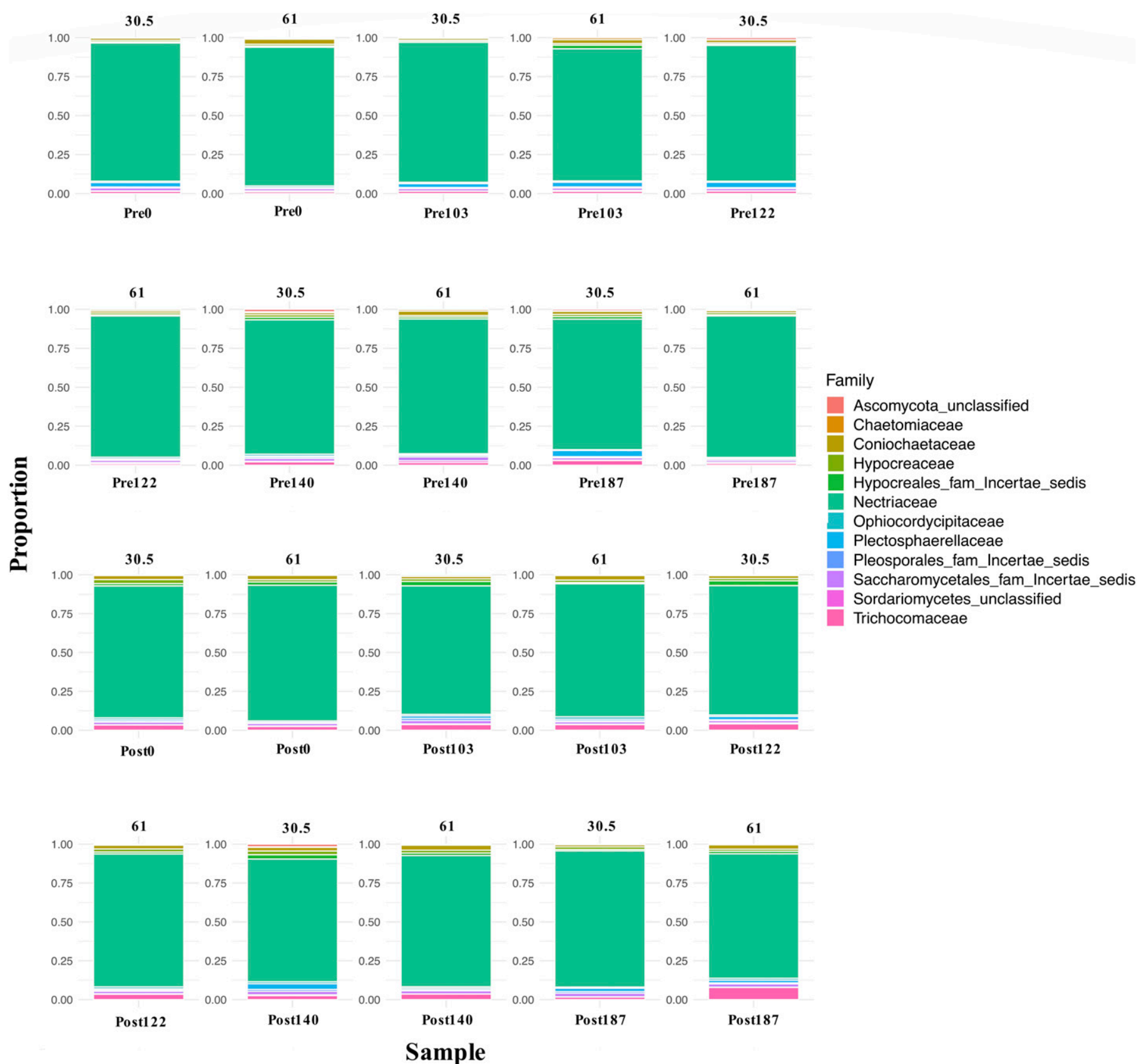

Fig. 3. Fungal community composition at family rank ( $>1 \%)$ presented by each plot with sampling depth and different rates of 1,3-dichloropropene applied in the pre- and posttreatment. 
Methylophilaceae, was lowered in response to 103 liters/ha, but its abundance increased in plots with fumigant at a rate of 122 liters/ha. In contrast, the abundances of five families (Flavobacteriales_ unclassified, Obscuribacterales_fa, Bacillaceae, Polyangiaceae, and Xanthomonadales_unclassified) increased in plots with 1,3-D at rates of 103,122 , or 140 liters/ha, while families including Cytophagia_unclassified, PHOS-HE5, Enterobacteriaceae, and an Unknown_Family in phylum Verrucomicrobia were positively affected by more than one rate. Enterobacteriaceae was the only family with consistent increasing abundances with higher rates of 1,3-D fumigation.

Certain families including Bacteroidales_unclassified, Cytophagia_unclassified, Simkaniaceae, Chlamydiales_unclassified, Selenomonadales_unclassified, and Alphaproteobacteria_unclassified displayed either more or less abundance in plots at $30.5 \mathrm{~cm}$ with applications of 1,3-D using different rates when compared with soil samples collected at $61 \mathrm{~cm}$ in untreated control plots.

Fungal community. We examined 139 fungal families where 24 families that belong to six phyla showed changes either between sample depths, with different rates of 1,3-D applied, or their interactions (Table 3). Most of these families that increased or decreased in abundance belong to Ascomycota. There were two families with abundances that differed between the two sample depths. Ophiocordycipitaceae had higher abundances in soil samples collected at $30.5 \mathrm{~cm}$ and the abundance of Cordycipitaceae was lower when compared with fungal community abundances from soil samples collected from $61 \mathrm{~cm}$.

There were two, three, seven, and four families that decreased in abundance, while one, two, one, and one family(s) increased in abundance in response to 1,3-D fumigation at rates of 103, 122, 140, and 187 liters/ha, respectively (Table 3 ). Of the families with increasing abundances, Microascales_unclassified, Lophiostomataceae, and Hyaloscyphaceae increased after fumigating with 1,3-D at rates of 103, 140, and 187 liters/ha, respectively, while Chaetomiaceae and Montagnulaceae both increased after application of 122 liters/ha. Among these families identified with decreasing

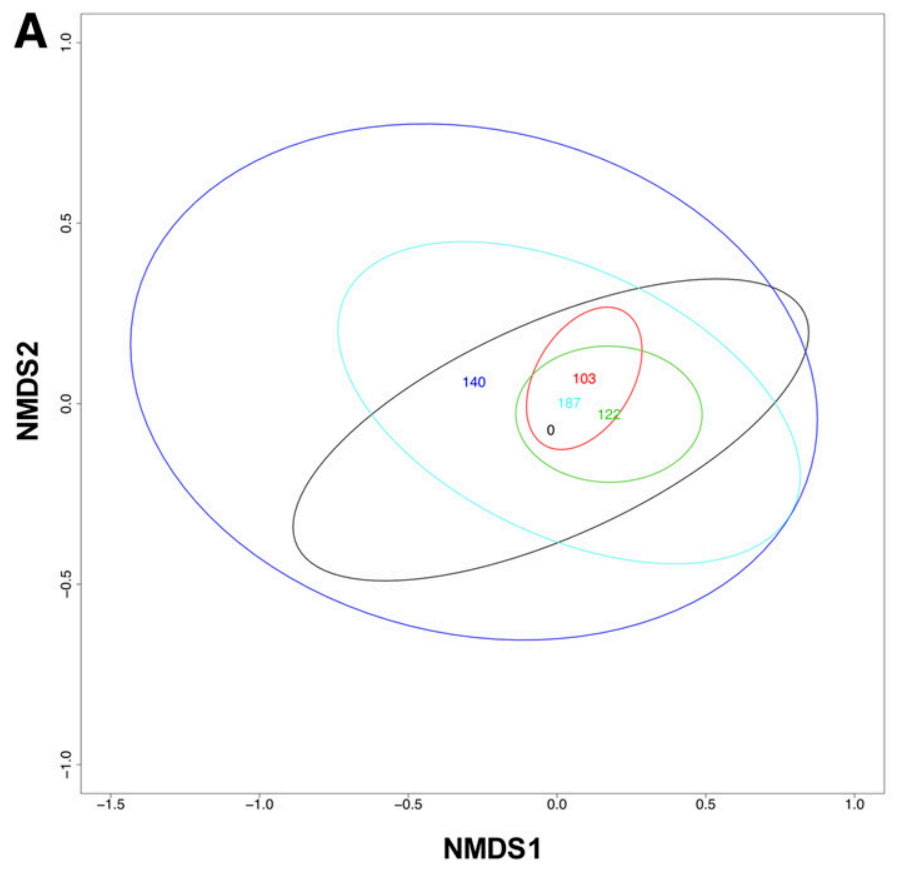

abundances, Ophiocordycipitaceae was the only family that displayed consistent decreasing trend in response to 1,3-D fumigation at 122,140 , and 187 liters/ha.

The abundances of six families, including Arachnomycetaceae, Lophiostomataceae, Microascales_unclassified, Montagnulaceae, Ophiostomataceae, and Claroideoglomeraceae, increased in plots at $30.5 \mathrm{~cm}$ with applications of 1,3-D at different rates when compared with soil samples collected at $61 \mathrm{~cm}$ in untreated control plots. In contrast, seven families (Botryosphaeriaceae, Coniochaetales_unclassified, Cordycipitaceae, Gymnoascaceae, Onygenaceae, Ophiocordycipitaceae, and Malasseziales_unclassified) showed decreasing trends of abundances in plots at $30.5 \mathrm{~cm}$ with applications of 1,3-D when compared with soil samples in untreated plots at $61 \mathrm{~cm}$ depth. Ophiocordycipitaceae was negatively affected at the upper level of soils through fumigation, regardless of the amount of 1,3-D applied.

\section{DISCUSSION}

Soil microflora is vital for healthy soil and is a source of genetic and metabolic diversity (Wang et al. 2015), but application of fumigants has become an essential practice to protect many crops from soilborne pathogens, nematodes, and weeds. Soil microorganisms experience disturbance (i.e., transient or intransient effects) upon application of fumigants, soil amendments, and other agricultural practices (Singh et al. 2015), but soil can be a robust ecosystem and fumigants may not have a long-term impact on the overall microbial community. We designed our experiment to determine if we could detect the impact of 1,3-D on the soil community approximately 1-month postfumigation, when 1,3-D treatment was included as part of typical farming operations.

We observed that posttreatment soils had higher bacterial and fungal richness and diversity than pretreatment soils, even in the pre- and post-control plots (Table 1). This suggests that moderate disturbance such as incorporation of cover crop into the entire experimental plot, and the irrigation and precipitation that occurred

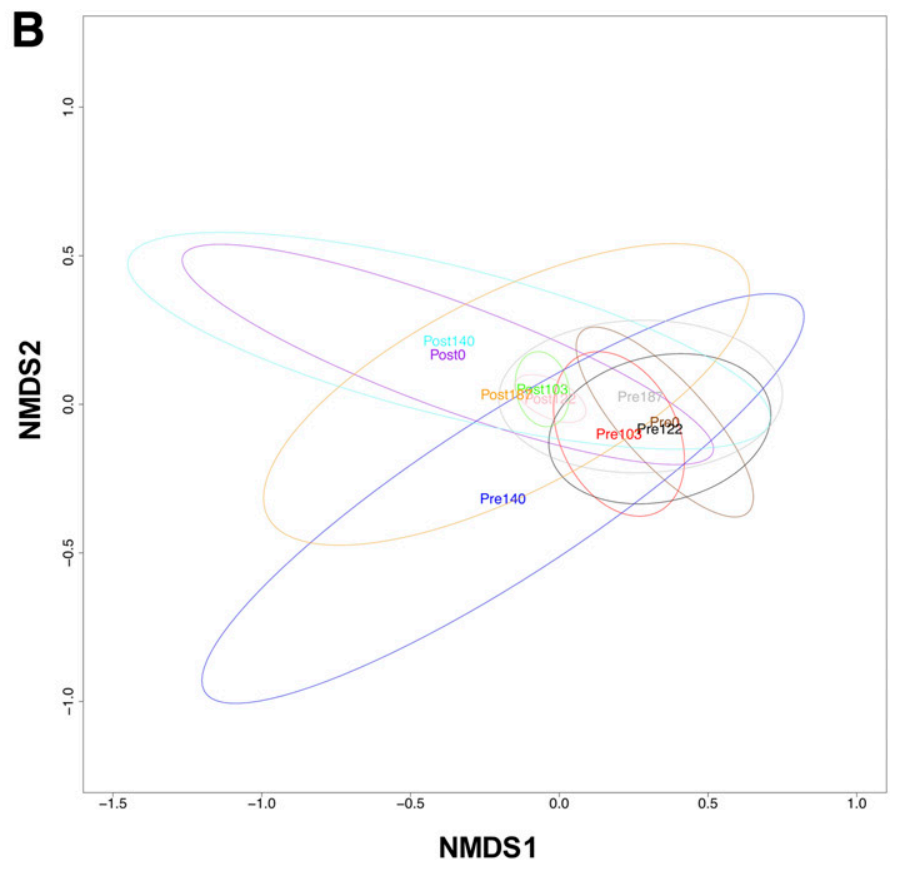

Fig. 4. Two-dimensional nonmetric multidimensional scaling (NMDS) based on Bray-Curtis dissimilarities of fungal community composition showing community composition A, among different rates of 1,3-dichloropropene (1,3-D) applied to plots and $\mathbf{B}$, among different rates of 1,3-D applied in preand posttreatment. 
TABLE 2

Bacterial phylum and families with significantly different abundances identified through linear mixed-effect regression models at a depth of $61 \mathrm{~cm}$ and no chemical (0 liters/ha) applied as reference levels ${ }^{\mathrm{a}}$

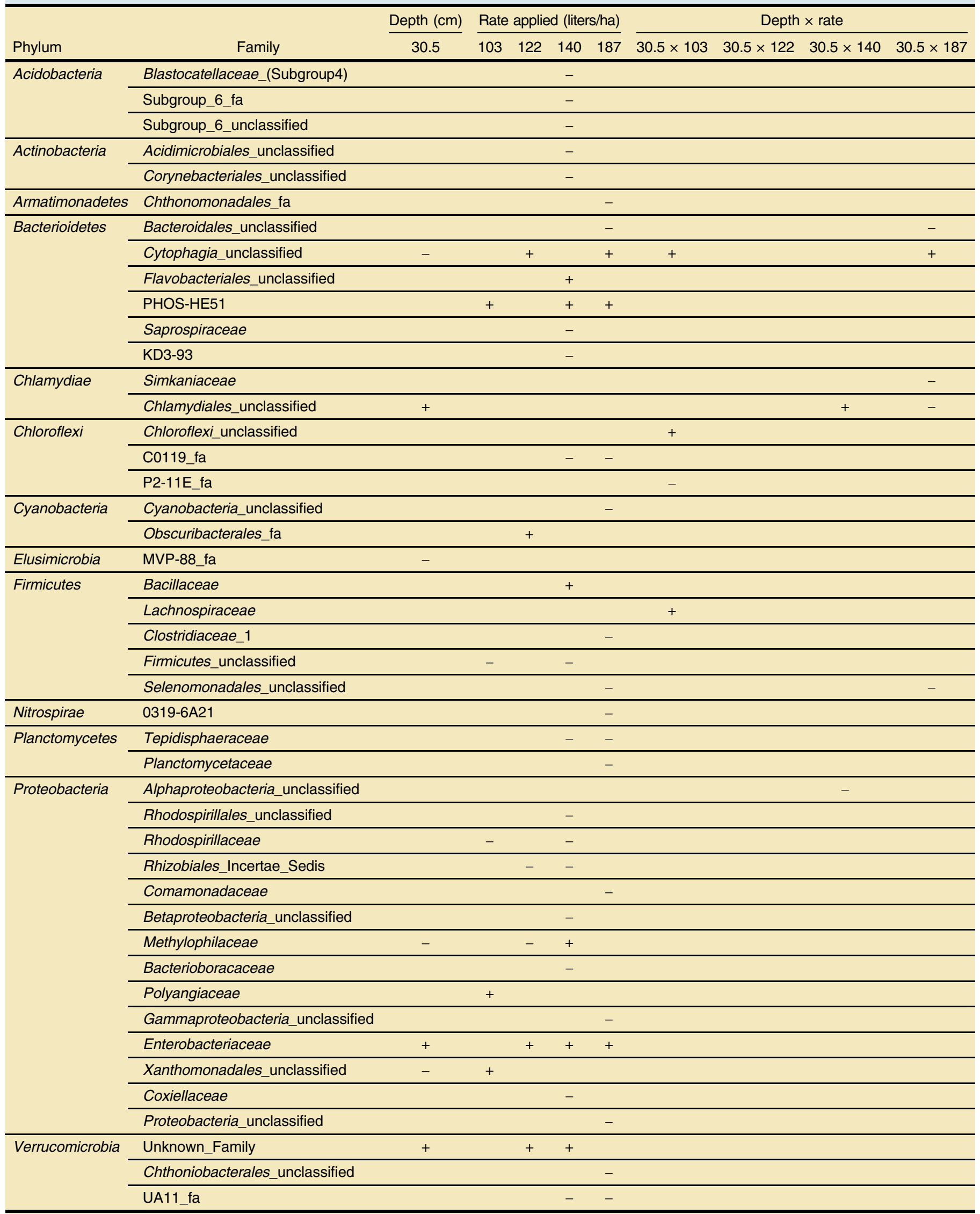

a $P$ S $<0.05, \alpha=0.05 ;+$, an increasing abundance; and - , a decreasing abundance. 
prior to the post-soil sampling, has a greater impact on bacterial and fungal communities in this soil ecosystem than did fumigation (Galand et al. 2016; Lancaster et al. 2010). Previous research reported that application of 1,3-D only had transient suppressive impacts on indigenous bacteria (Ibekwe et al. 2001; Liu et al. 2015); however, in the present study, increasing rates of 1,3-D to 122 and 140 liters/ha resulted in an enhanced bacterial richness in soils that was not observed in treatments that received 1,3-D at rates of 103 and 187 liters/ha when compared with control plots at the same sampling time. These results suggest that 1,3-D and other environmental factors might collectively drive the shift of bacterial community structure (Santoyo et al. 2017). In contrast, diversity and richness indices of fungal communities were not affected by 1,3-D fumigation which is in agreement with the results obtained by Hoshino and Matsumoto (2007), who studied the impact of 1,3-D on the fungal community in a Dystric-Silic Andisal, light clay spinach field.

Richness indices of bacterial community and diversity indices of fungal community were different in soil samples collected at two depths, with higher indices occurring at $30.5 \mathrm{~cm}$. NMDS was conducted to examine the effect of sampling time, depth, and 1,3-D fumigation on overall microbial community structure at the family level. Clear separations between pre- and posttreatment, at the two depths, and their interactions indicate that the soil microbial community varied interactively as a function of sampling time and depth. In contrast, the 1,3-D fumigation had no impact on overall microbial community profiles compared with untreated control plots (Figs. 2 and 4) although a few families showed altered abundances in response to 1,3-D fumigation. These findings are consistent with the relationships observed using a hierarchically clustered heatmap, except that microbial community profiles in plots from pre- and postsamples were mixed which might be attribute to similar soil physical properties among pre- and post-samples. It is also possible that temperature and humidity gradients as well as plant biomass influence soil microbial community structure at different depths (Mandakovic et al. 2018; Rui et al. 2015; Št'ovíček et al. 2017).

Similar to some previous studies that analyzed microbial community composition in various environments or in response to different treatments (Dong et al. 2017; Guo et al. 2015; Fang et al. 2015; Ma et al. 2016; Liu et al. 2015; Spain et al. 2009), three phyla, including Proteobacteria, Firmicutes, and Actinobacteria, were predominant across all soil samples. It is not surprising that Proteobacteria, a genetically and metabolically diverse, environmentally widespread, and ecologically important phylum was most abundant in our soil samples (Liu et al. 2015). Within this phylum, Gammaproteobacteria are responsible for utilizing propionate, butyrate, and acetate, and Alphaproteobacteria, which could

TABLE 3

Fungal phylum and families with significantly different abundances identified through linear mixed-effect regression models at a depth of $61 \mathrm{~cm}$ and no chemical (0 liters/ha) applied as reference levels ${ }^{a}$

\begin{tabular}{|c|c|c|c|c|c|c|c|c|c|c|}
\hline \multirow[b]{2}{*}{ Phylum } & \multirow[b]{2}{*}{ Family } & \multirow{2}{*}{$\frac{\text { Depth }(\mathrm{cm})}{30.5}$} & \multicolumn{4}{|c|}{$\begin{array}{l}\text { Rate applied } \\
\text { (liters/ha) }\end{array}$} & \multicolumn{4}{|c|}{ Depth $\times$ rate } \\
\hline & & & 103 & 122 & 140 & 187 & $30.5 \times 103$ & $30.5 \times 122$ & $30.5 \times 140$ & $30.5 \times 187$ \\
\hline \multirow{11}{*}{ Ascomycota } & Botryosphaeriaceae & & - & & & & - & & & \\
\hline & Chaetomiaceae & & & + & & & & & & \\
\hline & Gymnoascaceae & & & & & & - & & & \\
\hline & Hyaloscyphaceae & & & & & + & & & & \\
\hline & Hypocreales_unclassified & & & & & - & & & & \\
\hline & Lophiostomataceae & & & & + & & & & + & \\
\hline & Onygenaceae & & & & & & & & & - \\
\hline & Ophiocordycipitaceae & + & & - & - & - & - & - & - & - \\
\hline & Ophiostomataceae & & & & & & & & + & \\
\hline & Pyronemataceae & & - & & & & & & & \\
\hline & Saccharomycetales_fam_Incertae_sedis & & & - & & & & & & \\
\hline \multirow[t]{3}{*}{ Basidiomycota } & Bulleribasidiaceae & & & & - & & & & & \\
\hline & Malasseziales_unclassified & & & & - & & & & - & \\
\hline & Schizophyllaceae & & & & & - & & & & \\
\hline Chytridiomycota & Unclassified_Chytridiomycetes & & & & - & & & & & \\
\hline
\end{tabular}


decompose glucose were dominant (Garcia-Peña et al. 2011; Huang et al. 2018). Firmicutes was the dominant phylum ranked only second to Proteobacteria. Many Firmicutes produce endospores to survive extreme conditions (e.g., Bacilli, Clostridia), and are often encountered in soil (Fimlaid and Shen 2015; Janssen 2006). Actinobacteria, which play important roles related to organic material turnover and carbon cycling were also ubiquitous in our plots (Nielsen et al. 2014).

Among fungi, the dominant phylum was assigned to Ascomycota in all of the soil samples. This is in agreement with previous studies, which showed that Ascomycota accounted for more of the total sequences in soil samples as demonstrated by Illumina HiSeq sequencer (Dong et al. 2017; Schmidt et al. 2013). Three dominant classes within Ascomycota, Sordariomycetes, Eurotiomycetes, and Saccharomycetes, play critical roles in decomposition and nutrient cycling, and the high abundances of this phylum in the soil samples may be associated with a higher disease suppression ability (Shen et al. 2015).

Notably, more families from bacterial and fungal communities had reduced abundance than families with enriched abundance after 1,3-D fumigation, perhaps due to the broad biocidal activity of 1,3D. However, most families did not show consistent patterns of increasing or decreasing abundances correlated with 1,3-D fumigation (Tables 2 and 3). Among the microbial families that were significantly increased or suppressed in response to 1,3-D fumigation, most were not dominant families (Tables 2 and 3; Figs. 1 and 3 ). Of the dominant bacteria families, Enterobacteriaceae showed a greater abundance in plots with increased 1,3-D rates. Similarly, Liu et al. (2015) found that Enterobacteriaceae were greatly enriched in 1,3-D-fumigated plots compared with their relative abundance in control plots. This family includes many species that grow quickly and that are associated with invertebrates and these species tend to encode enzymes capable of degrading chitin. Death of nematodes and insects caused by 1,3-D may have provided bacteria from this family a nutrient source that supported increased growth of some Enterobacteriaceae species. Other dominant bacterial families, Firmicutes_unclassified and Gammaproteobacteria_unclassified displayed decreasing responses to 1,3-D fumigation. Interestingly, a parasitic fungal family, Ophiocordycipitaceae which belongs to Ascomycota, was negatively affected by 1,3-D fumigant with increasing rates. Some species within the family are nematode and insect parasitic fungi (Simmons et al. 2015; Zhang et al. 2017). It is likely that the decreasing abundance of Ophiocordycipitaceae were positively related to the reduction of nematode and insect populations by 1,3-D fumigants.

In this study, we demonstrated that 1,3-D fumigation did not significantly affect overall microbial community profiles nor microbial richness and diversity, although bacterial richness increased following application of 1,3-D at 140 liters/ha. Species from the bacterial family Enterobacteriaceae, which may be able to quickly metabolize dead invertebrates, and species from the family Ophiocordycipitaceae, which may be invertebrate pathogens, were altered in abundance in response to different rates of fumigation treatment. Based on the results, we propose that 1,3-D fumigation has only a minor overall effect on microbial community structure in sandy loam soils. However, future studies that determine if decreases in potential fungal pathogens of invertebrates in the Ophiocordycipitaceae allow nematode populations to recover quickly postfumigation may be warranted.

\section{ACKNOWLEDGMENTS}

We thank Kristen Otto at Colorado State University for laboratory assistance, and the editor and the anonymous reviewer for their excellent feedback that significantly improved this paper.

\section{LITERATURE CITED}

Ahmed, S., and Ahmad, M. S. 2006. Effect of insecticides on the total number of soil bacteria under laboratory and field conditions. Pak. Entomol. 28:63-68.

Aislabie, J., and Lloyd-Jones, G. 1995. A review of bacterial-degradation of pesticides. Soil Res. 33:925-942.

Ajwa, H. A., Klose, S., Nelson, S. D., Minuto, A., Gullino, M. L., Lamberti, F., and Lopez-Aranda, J. M. 2003. Alternatives to methyl bromide in strawberry production in the United States of America and the Mediterranean region. Phytopathol. Mediterr. 42:220-244.

Bai, Y., Qi, W., Liang, J., and Qu, J. 2014. Using high-throughput sequencing to assess the impacts of treated and untreated wastewater discharge on prokaryotic communities in an urban river. Appl. Microbiol. Biotechnol. 98: 1841-1851.

Bending, G. D., Rodríguez-Cruz, M. S., and Lincoln, S. D. 2007. Fungicide impacts on microbial communities in soils with contrasting management histories. Chemosphere 69:82-88.

Dennis, P. G., Kukulies, T., Forstner, C., Orton, T. G., and Pattison, A. B. 2018. The effects of glyphosate, glufosinate, paraquat and paraquat-diquat on soil microbial activity and bacterial, archaeal and nematode diversity. Sci. Rep. 8: 2119.

Dong, W., Si, P., Liu, E., Yan, C., Zhang, Z., and Zhang, Y. 2017. Influence of film mulching on soil microbial community in a rainfed region of northeastern China. Sci. Rep. 7:8468.

Dungan, R. S., Ibekwe, A. M., and Yates, S. R. 2003. Effect of propargyl bromide and 1,3-dichloropropene on microbial communities in an organically amended soil. FEMS Microbiol. Ecol. 43:75-87.

Fang, H., Lian, J., Wang, H., Cai, L., and Yu, Y. 2015. Exploring bacterial community structure and function associated with atrazine biodegradation in repeatedly treated soils. J. Hazard. Mater. 286:457-465.

Fimlaid, K. A., and Shen, A. 2015. Diverse mechanisms regulate sporulation sigma factor activity in the Firmicutes. Curr. Opin. Microbiol. 24:88-95.

Galand, P. E., Lucas, S., Fagervold, S. K., Peru, E., Pruski, A. M., Vétion, G., et al. 2016. Disturbance increases microbial community diversity and production in marine sediments. Front. Microbiol. 7:1950.

Garcia-Peña, E. I., Parameswaran, P., Kang, D. W., Canul-Chan, M., and Krajmalnik-Brown, R. 2011. Anaerobic digestion and co-digestion processes of vegetable and fruit residues: Process and microbial ecology. Bioresour. Technol. 102:9447-9455.

Guo, J., Peng, Y., Ni, B. J., Han, X., Fan, L., and Yuan, Z. 2015. Dissecting microbial community structure and methane-producing pathways of a fullscale anaerobic reactor digesting activated sludge from wastewater treatment by metagenomic sequencing. Microbiol. Cell Fact. 14:33.

Hernández-Allica, J., Becerril, J. M., Zárate, O., and Garbisu, C. 2006. Assessment of the efficiency of a metal phytoextraction process with biological indicators of soil health. Plant Soil 281:147-158.

Hoshino, Y. T., and Matsumoto, N. 2007. Changes in fungal community structure in bulk soil and spinach rhizosphere soil after chemical fumigation as revealed by $18 \mathrm{~S}$ rDNA PCR-DGGE. Soil Sci. Plant Nutr. 53:40-55.

Huang, X., Dong, W., Wang, H., and Feng, Y. 2018. Role of acid/alkalitreatment in primary sludge anaerobic fermentation: Insights into microbial community structure, functional shifts and metabolic output by highthroughput sequencing. Bioresour. Technol. 249:943-952.

Ibekwe, A. M., Papiernik, S. K., Gan, J., Yates, S. R., Yang, C. H., and Crowley, D. E. 2001. Impact of fumigants on soil microbial communities. Appl. Environ. Microbiol. 67:3245-3257.

Imfeld, G., and Vuilleumier, S. 2012. Measuring the effects of pesticides on bacterial communities in soil: A critical review. Eur. J. Soil Biol. 49:22-30.

Janssen, P. H. 2006. Identifying the dominant soil bacterial taxa in libraries of 16S rRNA and 16S rRNA genes. Appl. Environ. Microbiol. 72:1719-1728.

Ji, X., Qiao, K., Dong, S., Wang, H., Xia, X., and Wang, K. 2013. Effects of 1,3dichloropropene plus chloropicrin on weed seed germination. Crop Prot. 45: $1-5$.

Lancaster, S. H., Hollister, E. B., Senseman, S. A., and Gentry, T. J. 2010. Effects of repeated glyphosate applications on soil microbial community composition and the mineralization of glyphosate. Pest Manag. Sci. 66:59-64.

Larkin, R. P. 2003. Characterization of soil microbial communities under different potato cropping systems by microbial population dynamics, substrate utilization, and fatty acid profiles. Soil Biol. Biochem. 35: 1451-1466.

Lewis, S. E., Brodie, J. E., Bainbridge, Z. T., Rohde, K. W., Davis, A. M., Masters, B. L., et al. 2009. Herbicides: A new threat to the Great Barrier Reef. Environ. Pollut. 157:2470-2484. 
Liu, X., Cheng, X., Wang, H., Wang, K., and Qiao, K. 2015. Effect of fumigation with 1,3-dichloropropene on soil bacterial communities. Chemosphere 139:379-385.

Luo, L., Yates, S. R., Ashworth, D. J., Xuan, R., and Becker, J. O. 2013. Effect of films on 1,3-dichloropropene and chloropicrin emission, soil concentration, and root-knot nematode control in a raised bed. J. Agric. Food Chem. 61:2400-2406.

Ma, B., Wang, H., Dsouza, M., Lou, J., He, Y., Dai, Z., et al. 2016. Geographic patterns of co-occurrence network topological features for soil microbiota at continental scale in eastern China. ISME J. 10:1891-1901.

Mandakovic, D., Rojas, C., Maldonado, J., Latorre, M., Travisany, D., Delage, E., et al. 2018. Structure and co-occurrence patterns in microbial communities under acute environmental stress reveal ecological factors fostering resilience. Sci. Rep. 8:5875.

Mao, L., Jiang, H., Zhang, L., Zhang, Y., Sial, M. U., Yu, H., and Cao, A. 2017. Replacing methyl bromide with a combination of 1,3-dichloropropene and metam sodium for cucumber production in China. PLoS One 12:e188137.

Maul, J. E., Buyer, J. S., Lehman, R. M., Culman, S., Blackwood, C. B., Roberts, D. P., et al. 2014. Microbial community structure and abundance in the rhizosphere and bulk soil of a tomato cropping system that includes cover crops. Appl. Soil Ecol. 77:42-50.

McMurdie, P. J., and Holmes, S. 2013. phyloseq: an R package for reproducible interactive analysis and graphics of microbiome census data. PLoS One 8:e61217.

Nielsen, S., Minchin, T., Kimber, S., van Zwieten, L., Gilbert, J., Munroe, P., et al. 2014. Comparative analysis of the microbial communities in agricultural soil amended with enhanced biochars or traditional fertilizers. Agric. Ecosyst. Environ. 191:73-82.

Oksanen, J., Blanchet, F. G., Kindt, R., Legendre, P., Minchin, P. R., O'Hara, R. B., et al. 2013. Package 'vegan'. Community Ecol. Package. Version, 2.

Pisa, L. W., Amaral-Rogers, V., Belzunces, L. P., Bonmatin, J. M., Downs, C. A., Goulson, D., et al. 2015. Effects of neonicotinoids and fipronil on nontarget invertebrates. Environ. Sci. Pollut. Res. 22:68-102.

Paulson, J. N., Stine, O. C., Bravo, H. C., and Pop, M. 2013. Robust methods for differential abundance analysis in marker gene surveys. Nat. Methods 10; 1200-1202.

Qiao, K., Jiang, L., Wang, H., Ji, X., and Wang, K. 2010. Evaluation of 1,3dichloropropene as a methyl bromide alternative in tomato crops in China. J. Agric. Food Chem. 58:11395-11399.

Qiao, K., Shi, X., Wang, H., Ji, X., and Wang, K. 2011. Managing root-knot nematodes and weeds with 1,3-dichloropropene as an alternative to methyl bromide in cucumber crops in China. J. Agric. Food Chem. 59:2362-2367.

Qin, R., Gao, S., and Ajwa, H. 2013a. Emission and distribution of fumigants as affected by soil moistures in three different textured soils. Chemosphere 90 : 866-872.

Qin, R., Gao, S., Thomas, J. E., Dickson, D. W., Ajwa, H., and Wang, D. 2013b. Emissions from soil fumigation in two raised bed production systems tarped with low permeability films. Chemosphere 93:1379-1385.

Rui, J., Li, J., Wang, S., An, J., Liu, W. T., Lin, Q., et al. 2015. Responses of bacterial communities to simulated climate changes in alpine meadow soil of Qinghai-Tibet plateau. Appl. Environ. Microbiol. 81:6070-6077.

Santoyo, G., Pacheco, C. H., Salmerón, J. H., and León, R. H. 2017. The role of abiotic factors modulating the plant-microbe-soil interactions: Toward sustainable agriculture. A review. Span. J. Agric. Res. 15:e03R01.

Schloter, M., Nannipieri, P., Sørensen, S. J., and van Elsas, J. D. 2018. Microbial indicators for soil quality. Biol. Fertil. Soils 54:1-10.

Schmidt, P. A., Bálint, M., Greshake, B., Bandow, C., Römbke, J., and Schmitt, I. 2013. Illumina metabarcoding of a soil fungal community. Soil Biol. Biochem. 65:128-132.
Shen, Z., Ruan, Y., Wang, B., Zhong, S., Su, L., Li, R., and Shen, Q. 2015. Effect of biofertilizer for suppressing Fusarium wilt disease of banana as well as enhancing microbial and chemical properties of soil under greenhouse trial. Appl. Soil Ecol. 93:111-119.

Shi, K., Wang, L., Zhou, Y. H., Yu, Y. L., and Yu, J. Q. 2009. Effects of calcium cyanamide on soil microbial communities and Fusarium oxysporum f. sp. cucumberinum. Chemosphere 75:872-877.

Simmons, D. R., Kepler, R. M., Rehner, S. A., and Groden, E. 2015. Phylogeny of Hirsutella species (Ophiocordycipitaceae) from the USA: Remedying the paucity of Hirsutella sequence data. IMA Fungus 6:345-356.

Singh, S., Gupta, R., Kumari, M., and Sharma, S. 2015. Nontarget effects of chemical pesticides and biological pesticide on rhizospheric microbial community structure and function in Vigna radiata. Environ. Sci. Pollut. Res. 22:11290-11300.

Sivanesan, S. D., Krishnamurthi, K., Wachasunder, S. D., and Chakrabarti, T. 2004. Genotoxicity of pesticide waste contaminated soil and its leachate. Biomed. Environ. Sci. 17:257-265.

Spain, A. M., Krumholz, L. R., and Elshahed, M. S. 2009. Abundance, composition, diversity and novelty of soil Proteobacteria. ISME 3:992-1000.

Št'ovíček, A., Azatyan, A., Soares, M. I. M., and Gillor, O. 2017. The impact of hydration and temperature on bacterial diversity in arid soil mesocosms. Front. Microbiol. 8:1078.

Sugita, N., Agemori, H., and Goka, K. 2018. Acute toxicity of neonicotinoids and some insecticides to first instar nymphs of a non-target damselfly, Ischnura senegalensis (Odonata: Coenagrionidae), in Japanese paddy fields. Appl. Entomol. Zool. 53:519-524.

Van der Sluijs, J. P., Amaral-Rogers, V., Belzunces, L. P., Van Lexmond, M. B., Bonmatin, J. M., Chagnon, M., et al. 2015. Conclusions of the Worldwide Integrated Assessment on the risks of neonicotinoids and fipronil to biodiversity and ecosystem functioning. Environ. Sci. Pollut. Res. 22:148-154.

Wang, D., Gao, S., Qin, R., and Browne, G. 2010. Lateral movement of soil fumigants 1,3-dichloropropene and chloropicrin from treated agricultural fields. J. Environ. Qual. 39:1800-1806.

Wang, Q., Garrity, G. M., Tiedje, J. M., and Cole, J. R. 2007. Naive Bayesian classifier for rapid assignment of rRNA sequences into the new bacterial taxonomy. Appl. Environ. Microbiol. 73:5261-5267.

Wang, X., Cui, H., Shi, J., Zhao, X., Zhao, Y., and Wei, Z. 2015. Relationship between bacterial diversity and environmental parameters during composting of different raw materials. Bioresour. Technol. 198:395-402.

Westcott, S. L., and Schloss, P. D. 2015. De novo clustering methods outperform reference-based methods for assigning 16S rRNA gene sequences to operational taxonomic units. PeerJ 3:e1487.

Wu, X., Xu, J., Dong, F., Liu, X., and Zheng, Y. 2014. Responses of soil microbial community to different concentration of fomesafen. J. Hazard. Mater. 273:155-164.

Zaller, J. G., Cantelmo, C., Dos Santos, G., Muther, S., Gruber, E., Pallua, P., et al. 2018. Herbicides in vineyards reduce grapevine root mycorrhization and alter soil microorganisms and the nutrient composition in grapevine roots, leaves, xylem sap and grape juice. Environ. Sci. Pollut. Res. 25:23215-23226.

Zhang, M., Teng, Y., Xu, Z., Wang, J., Christie, P., and Luo, Y. 2016. Cumulative effects of repeated chlorothalonil application on soil microbial activity and community in contrasting soils. J. Soils Sediments 16:1754-1763.

Zhang, Y. J., Zhang, H. Y., Liu, X. Z., and Zhang, S. 2017. Mitochondrial genome of the nematode endoparasitic fungus Hirsutella vermicola reveals a high level of synteny in the family Ophiocordycipitaceae. Appl. Microbiol. Biotechnol. 101:3295-3304. 